\title{
Acute Septic Arthritis due to Streptococcus sanguis
}

\author{
Demetrios Papaioannides $^{\mathrm{a}}$ Loukia Boniatsi $^{\mathrm{b}}$ Panagiotis Korantzopoulos ${ }^{\mathrm{c}}$ \\ Demetrios Sinapidis ${ }^{c}$ Christos Giotis ${ }^{c}$ \\ Departments of a Medicine and ${ }^{\mathrm{b}}$ Microbiology, Psychiatric Hospital of Attica, Athens, and \\ ${ }^{c}$ Department of Medicine, Arta General Hospital, Arta, Greece
}

\section{Key Words}

Septic arthritis - Bacterial arthritis ·

Streptococcus sanguis $\cdot$ Streptococcus viridans

\begin{abstract}
Objective: To present a case of acute septic arthritis due to Streptococcus sanguis, a member of the viridans group streptococci. Clinical Presentation and Intervention: A 73-year-old woman presented with fever and increasing swelling and pain of the right knee several weeks after she had been treated for severe periodontal disease. Arthrocentesis yielded purulent synovial fluid. S. sanguis was isolated in synovial fluid cultures, and the patient was treated with intravenous cefotaxime for 3 weeks and repeated aspiration of the knee joint with gradual resolution of fever, joint swelling and effusion. Conclusion: Although $S$. sanguis is believed to be a rare cause of septic arthritis in native joints, it should be considered in the differential diagnosis of this disorder, especially in patients with recent treatment of severe dental caries and periodontal disease.
\end{abstract}

Copyright $(2006$ S. Karger AG, Basel

\section{Introduction}

Despite advances in antimicrobial and surgical therapy, septic arthritis remains a rheumatological emergency that can lead to rapid joint destruction and irreversible loss of function. In adults, Staphylococcus aureus is the most common bacterium isolated from native joints, found in $40-60 \%$ of a large series [1]. After S. aureus, $\beta$-hemolytic streptococci are the most common cause of bacterial arthritis; in contrast, viridans streptococci are rarely associated with joint infection [2]. We describe here a case of septic arthritis due to Streptococcus sanguis (a member of the viridans streptococcal group) in a woman with severe osteoarthritis of the knees and periodontal disease.

\section{Case Report}

A 73-year-old woman suffering from severe osteoarthritis of the knees and spine presented with fever and increasing swelling and pain of the right knee. During the last month, the patient had been treated for severe periodontal disease, and the last treatment had been carried out 20 days before admission. No antibiotics were prescribed, and the patient on occasion used diclofenac or paracetamol for relief of the joint pain. She came to the hospital with a painful, swollen, warm right knee that had begun 6 days earlier, and fever, anorexia, malaise and chills. On physical examina-

\begin{tabular}{ll}
\hline KARGER & ( ) 2006 S. Karger AG, Basel \\
1011-7571/06/0151-0077\$23.50/0 \\
$\begin{array}{l}\text { Fax +4161306 } 1234 \\
\begin{array}{l}\text { E-Mail karger@karger.ch } \\
\text { www.karger.com }\end{array}\end{array}$ & $\begin{array}{l}\text { Accessible online at: } \\
\text { www.karger.com/mpp }\end{array}$
\end{tabular}

D. Papaioannides, MD

Department of Medicine, Psychiatric Hospital of Attica El. Venizelou 13 GR-19004 Spata (Greece)

Tel. +302106025492, Fax +302106630113, E-Mail dipapaio@otenet.gr 
tion, the patient's temperature was $38.2^{\circ} \mathrm{C}$, blood pressure was $155 / 88 \mathrm{~mm} \mathrm{Hg}$, and pulse was 94 beats/min. There were no cardiac murmurs, hepatosplenomegaly or rash. The right knee was swollen, warm and tender with a large synovial effusion and severe functional impairment. In the initial laboratory evaluation, her hemoglobin concentration was $12.2 \mathrm{~g} / \mathrm{dl}$, the leukocyte count was $11,800 / \mathrm{mm}^{3}$ (with a neutrophilic predominance), and the erythrocyte sedimentation rate was elevated at $80 \mathrm{~mm} / \mathrm{h}$. Findings of a urinalysis were normal. A plain X-ray of the right knee showed severe degenerative changes with subchondral sclerosis and narrowing of the articular space. A chest X-ray was normal. A transesophageal echocardiogram did not detect any vegetation on the cardiac valves. Arthrocentesis of the right knee performed at admission yielded synovial fluid with 54,000 cells $/ \mathrm{mm}^{3}$ (95\% polymorphonuclear leukocytes), glucose $40 \mathrm{mg} / \mathrm{dl}$ (simultaneous glycemia $98 \mathrm{mg} / \mathrm{dl}$ ) and total protein $4 \mathrm{~g} / \mathrm{dl}$. There were no crystals on microscopic examination under polarized light, and a Gram stain was negative. S. sanguis was isolated in synovial fluid cultures but not in blood or urine cultures. Therapy with intravenous cefotaxime at a dose of $8 \mathrm{~g} /$ day for 3 weeks and repeated aspiration of the knee joint was followed by the gradual disappearance of fever, joint swelling and effusion. There was no relapse of the arthritis after a follow-up of 6 months, and the patient remains asymptomatic.

\section{Discussion}

Streptococcal septic arthritis accounts for $15-30 \%$ of all nongonococcal causes of bacterial arthritis in adults [1]. Most infections are due to S. pyogenes (group A), but group B (S. agalactiae) and group G streptococci are well reported, especially in patients with underlying predisposing conditions, such as diabetes, malignancy, alcoholism or established joint disease [1, 3, 4].

$S$. viridans has a low virulence, and infection by this microorganism usually appears on a previously injured focus [2]. However, its association with dental caries and bacterial endocarditis has been well established [2, 4]. Septic arthritis due to the viridans group of streptococci has been reported rarely. Comprehensive reviews of the topic do not mention viridans group streptococci as etiological agents in septic arthritis [5]. However, some isolated cases have been identified, mainly affecting the knee, sternoclavicular, acromioclavicular and sacroiliac joints [2, 6-8]. In one of these cases, septic arthritis was associated with bacterial endocarditis [8]. In the case of Blankstein et al. [7], minor trauma preceded shortly the development of the septic process. Recently, Weber et al. [9] have reported 3 cases of spondylodiscitis caused by viridans streptococci.

$S$. sanguis, a member of the viridans group of streptococci, is a well-known commensal of the mouth, upper respiratory tract, lower intestinal tract, genitourinary tract and skin of healthy humans [4]. There are only three previous reports of septic arthritis due to $S$. sanguis [1012]. Nitsche et al. [10] described a young man with polymicrobial infection of the sternoclavicular joint due to S. sanguis and Pasteurella multocida. The authors believed that the primary infective agent was probably $P$. multocida and that $S$. sanguis was introduced secondarily at the time of local injection of corticosteroids for relief of the arthritic pain in the sternoclavicular joint, 10 days before admission to the hospital. Patrick and Lewis [11] described a previously healthy 56-year-old man with obvious dental caries who had septic arthritis of the knee due to $S$. sanguis. In the report by Edson et al. [12], a 66-year-old man developed septic arthritis of the knee due to $S$. sanguis after he had been treated for severe periodontal disease, which likely contributed to his joint sepsis through hematogenous spread. To our knowledge, our case represents the third documented case of monomicrobial septic arthritis due to $S$. sanguis. Our patient had had treatment for periodontal disease before the development of septic arthritis. Although blood cultures at the time of admission were negative, it is postulated that she experienced transient bacteremia from a dental source leading to involvement of a previously abnormal knee joint.

\section{Conclusion}

Although viridans group streptococci in general and $S$. sanguis in particular are rare causes of septic arthritis in native joints, they should be considered in the differential diagnosis of this disorder, especially in the setting of severe periodontal disease and dental caries. 


\section{References}

1 Peters RH, Rasker JJ, Jacobs JW, Prevo RL, Karthaus PP: Bacterial arthritis in a district hospital. Clin Rheumatol 1992;11:351-355.

$>2$ Barbadillo C, Trujillo A, Cuende E, Mazzucchelli R, Mulero J, Andreu JL: Septic arthritis due to Streptococcus viridans. Clin Exp Rheumatol 1990;8:520-521.

$>3$ Vartian C, Lerner PI, Shlaes DM, Gopalakrishna KV: Infections due to Lancefield group G streptococci. Medicine (Baltimore) 1985;64: 75-88.

4 Johnson CC, Tunkel AR: Viridans streptococci, groups $\mathrm{C}$ and $\mathrm{G}$ streptococci, and Gemella morbillorum; in Mandell GL, Bennett JE, Dolin R (eds): Mandell, Douglas, and Bennett's Principles and Practice of Infectious Diseases, ed 6. Philadelphia, Elsevier Churchill Livingstone, 2005, pp 2434-2451.
5 Pioro MH, Mandell BF: Septic arthritis. Rheum Dis Clin North Am 1997;23:239_ 258.

6 Mata P, Molins A, De Oya M: Sternal arthritis caused by Streptococcus viridans in a heroin addict. Med Clin 1984;83:689.

-7 Blankstein A, Amsallem JL, Rubinstein E, Horoszowski H, Farin I: Septic arthritis of the acromioclavicular joint. Arch Orthop Trauma Surg 1985;103:417-418.

8 Fossaluzza V, Tosato F, Rossi P, Udina P: Bacterial endocarditis caused by Streptococcus viridans disclosed by sacroiliitis. Rev Rhum Mal Ostéoartic 1987;54:79. $\checkmark 9$ Weber M, Gubler J, Fahrer H, Crippa M, Kissling R, Boos N, Gerber H: Spondylodiscitis caused by viridans streptococci: three cases and review of the literature. Clin Rheumatol 1999; 18:417-421.

10 Nitsche JF, Vaughan JH, Williams G, Curd JG: Septic sternoclavicular arthritis with Pasteurella multocida and Streptococcus sanguis. Arthritis Rheum 1982;25:467-469.

11 Patrick MR, Lewis D: Short of a length: Streptococcus sanguis knee infection from dental source. Br J Rheumatol 1992;31:569.

12 Edson RS, Osmon DR, Berry DJ: Septic arthritis due to Streptococcus sanguis. Mayo Clin Proc 2002;77:709-710. 